\title{
Utilizing technology acceptance model (TAM) for driverless car technology adoption
}

\author{
Sahil Koul ${ }^{*}$, Ali Eydgahi $^{2}$
}

\begin{abstract}
This paper examines the relationship between perceived usefulness of driverless car technology, perceived ease of use of driverless car technology, years of driving experience, age and the intention to use driverless cars. This research is a cross-sectional descriptive correlational study with the Technology Acceptance Model as its theoretical framework. The primary method of data collection was an online survey. Pearson's correlation and multiple linear regression were used for data analysis. This study found significant, positive relationships between perceived usefulness of driverless car technology, perceived ease of use of driverless car technology and intention to use driverless cars. Also, there were significant, negative relationships between years of driving experience, age and intention to use driverless cars.
\end{abstract}

Keywords: driverless car technology adoption; technology acceptance model; innovation adoption; society; autonomous vehicles

Submitted: May $11^{\text {th }}, 2018 /$ Approved: November $27^{\text {th }}, 2018$

\section{Introduction}

The global automotive industry is now at a turning point for the transportation phase change due to driverless car technology (DCT), which potentially has groundbreaking economic, regulatory, and social implications (Bansal, Kockelman, \& Singh, 2016; Gadepally, 2013; Howard \& Dai, 2014; Knight, 2013; Maarafi, 2015). DCT represents a disruptive change that could potentially revive the concept of single occupancy cars and initiate a socio-cultural revolution (Brett, 2016). A driverless car (DC) is an unmanned vehicle that is capable of maneuvering without human input but utilizes the support of several sophisticated sub-systems and devices (Owczarzak \& Żak, 2015).

DCT has its roots as far back as 1926 when Achen motors, an automotive distributor, demonstrated a 'phantom car tour' around the city of Milwaukee (Menon, 2015). However, it was not until 2005 when Stanley, the winning robot of Defense Advanced Research Projects Agency (DARPA) Urban Challenge, completed the 150-mile obstacle course and provided more realistic technological solutions regarding the feasibility of DCT (Guerra, 2016; Thrun et al., 2006).

The consumers of the automobile industry have experienced many incremental automation changes to the cars driven today (Jiang, Petrovic, Ayyer, Tolani, \& Husain, 2015). Collision avoidance system, park assist, adaptive cruise control, and lane change assist are some examples of the driver assistance systems that are currently available commercially (Howard \& Dai, 2014; Zindler \& Geiss, 2016). These systems provide car manufacturers with building blocks that ultimately furnish the role of feeding into DCT (Howard \& Dai, 2014).

Research has validated that social change is a consequence of technological change (Mohd, Ahmad, Samsudin, \& Sudin, 2011). Automation cannot achieve its potential if its latent users do not adopt and if it is associated with improper reliance during early stages of implementation (Ghazizadeh, Lee, \& Boyle, 2012).
For DCT to be successful shortly, gaining social acceptance and anticipating factors impacting the adoption of DCT from the perspective of users has to be researched in-depth (Bansal et al., 2016; Heide \& Henning, 2006; Menon, 2015; Payre, Cestac, \& Delhomme, 2014). The literature shows evidence that the technology of DC is considerably ahead of the research examining the social acceptance of this technology (Guerra, 2016). Moreover, existing studies within this domain seem to differ in the results of DCT acceptance with varying demographics and geography. The leadership of automobile organizations could benefit from the new data, regarding the factors influencing acceptance of DCT, which will facilitate their decision-making and guide resources towards an appropriate direction.

The societal benefits of DCT, such as providing mobility solutions for all consumers regardless of their age, skills, and ability (Brett, 2016), warrant in-depth research into the social acceptance of this technology. Understanding the factors that influence the consumer adoption structure of DCT will guide the future research of more dependable and socially acceptable vehicles (Matthews, 2016).

The purpose of this study was to determine whether there is a relationship between the perceived usefulness of driverless car technology, perceived ease of use of driverless car technology, years of driving experience, age (independent constructs) and the intention to use driverless cars (dependent construct).

The perceived usefulness of DCT was the extent to which potential consumers of DC perceive this technology enhances their mobility, which eventually may influence their intentions to use DC. The perceived ease of use of DCT was the extent to which potential consumers of DC perceive the degree of ease associated with this technology, which eventually may influence their intentions to use DC. The intention to use DC construct represented the behavioral intention of potential consumers to adopt DC.

(1) College of Technology, Eastern Michigan University, Michigan, USA.

(2) School of Engineering Technology, Eastern Michigan University, Michigan, USA

*Corresponding author: skoul@emich.edu 


\section{Technology Acceptance Model}

The Technology Acceptance Model (TAM; Davis, 1989) will continue to remain the hotspot of research as new technologies are evolving (Horton, Buck, Waterson, \& Clegg, 2001; Venkatesh, Davis, \& Morris, 2007). TAM is one of the most effective and widely used information systems theoretical frameworks (Holden \& Karsh, 2010; Lee, Kozar, \& Larsen, 2003; Li, 2010).
As shown in Figure 1, TAM is a proven powerful framework for determination of early user acceptance and the original scale measures the TAM constructs within the context of different technologies across populations and is sufficiently validated (Davis \& Venkatesh, 1996). An early indication of user acceptance becomes critical when huge financial implications are associated, especially with new, emerging technologies (Davis, 1993).

Figure 1. TAM model. Adapted from Davis \& Venkatesh, 1996, p. 20.

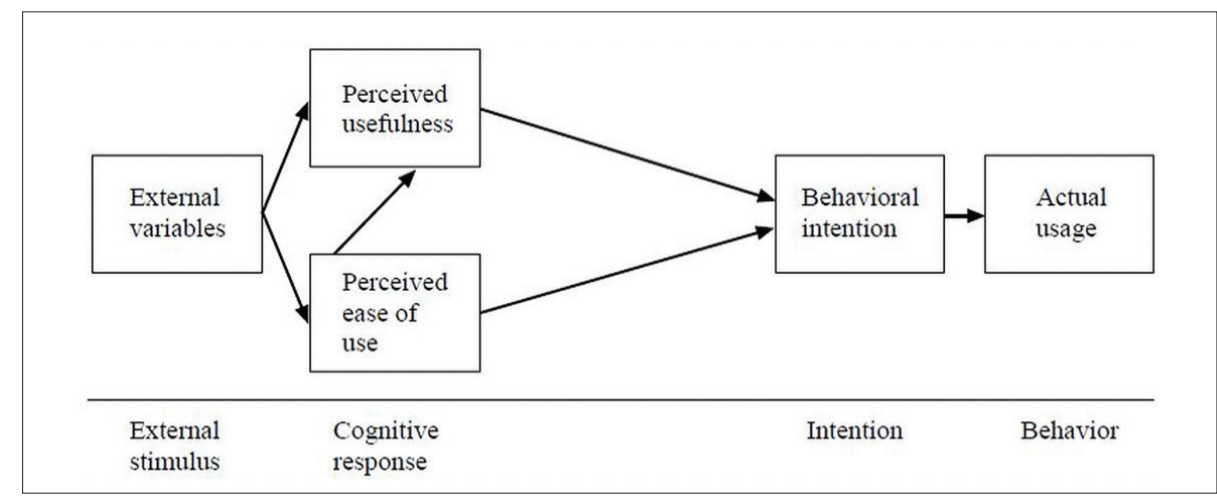

\section{Research Model}

The most common usage of TAM has evolved to be the determinant of the relationship between perceived usefulness (PU), perceived ease of use (PEOU), and anticipated future usage of many emerging technologies (Horton et al., 2001). The reliability of the items of the TAM constructs measured via Cronbach's alpha has been found to exceed 0.9 across numerous studies (Davis \& Venkatesh, 1996; Yousafzai, Foxall, \& Pallister, 2007a). TAM has found its application in various settings, such as, but not limited to, online learning, social networking media, intranet, and smartphones. For example, a study of factors influencing attitudes towards adoption of mobile commerce provided empirical evidence that the TAM model can be applied to the field of mobile commerce and provided sufficient explanation of consumer adoption intentions (Yang, 2005). Similarly, another study on the acceptance of advanced mobile services validated the application of TAM (LópezNicolás, Molina-Castillo, \& Bouwman, 2008). Further, Jansson, Marell, and Nordlund (2010) explored the factors regarding consumers' adoption associated with alternate fuel eco-friendly car technology.
The research model of this study is shown in Figure 2. The current literature on DCT adoption constitutes of descriptive univariate analysis. This work attempted to apply the theoretical constructs available from TAM to the domain of DCT adoption. The study conducted by Schoettle and Sivak (2014) provides valuable information about the general perceptions of potential consumers of DCT. However, this paper aims to build more specificity by examining relational aspects between technology acceptance constructs and the intention to use DC.

Similarly, Menon (2015) pointed out that the factors influencing adoption of DCT can potentially change over time and as technology evolves. This study attempts along a similar path to ascertain consumers' perceptions in a different setting and, thus, to present new data. Further, investigating the acceptance of driverless car technology by Nees (2016) concluded that acceptance of DCT was low in older people and people with more driving experience. This study attempted to confirm these results in a different setting.

Figure 2. Research Model.

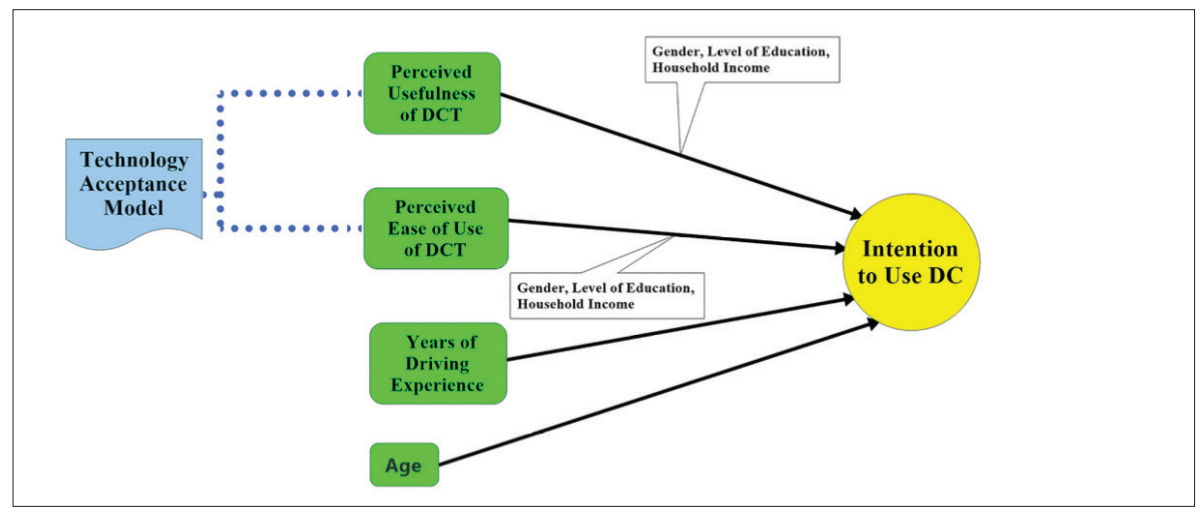

ISSN: 0718-2724. (http://jotmi.org) 


\section{Methodology}

The cross-sectional, descriptive, correlational research design was the underlying methodology of this study, which obtained quantitative data regarding consumers' perceptions of fully driverless transportation in the U.S. The research questions that are addressed in this study are as follows:

Q1: To what extent does a relationship exist between the perceived usefulness of driverless car technology and the intention to use driverless cars?

Q2: To what extent does a relationship exist between the perceived ease of use of driverless car technology and the intention to use driverless cars?

Q3: To what extent does a relationship exist between the number of years of driving experience and the intention to use driverless cars? Q4: To what extent does a relationship exist between age and the intention to use driverless cars?
Q5: To what extent do the socio-economic demographic variables (Gender, Level of Education, and Household Income) moderate the relationship between the perceived usefulness of driverless car technology and the intention to use driverless cars?

Q6: To what extent do the socio-economic demographic variables (Gender, Level of Education, and Household Income) moderate the relationship between the perceived ease of use of driverless car technology and the intention to use driverless cars?

Q7: What is the combined impact of perceived usefulness of driverless car technology, perceived ease of use of driverless car technology, number of years of driving experience, and age on the intention to use driverless cars?

\section{Instrument}

The study utilized modified versions of existing instruments and items used for each construct are discussed in Table 1.

Table 1. tems Utilized in the Study Instrument.

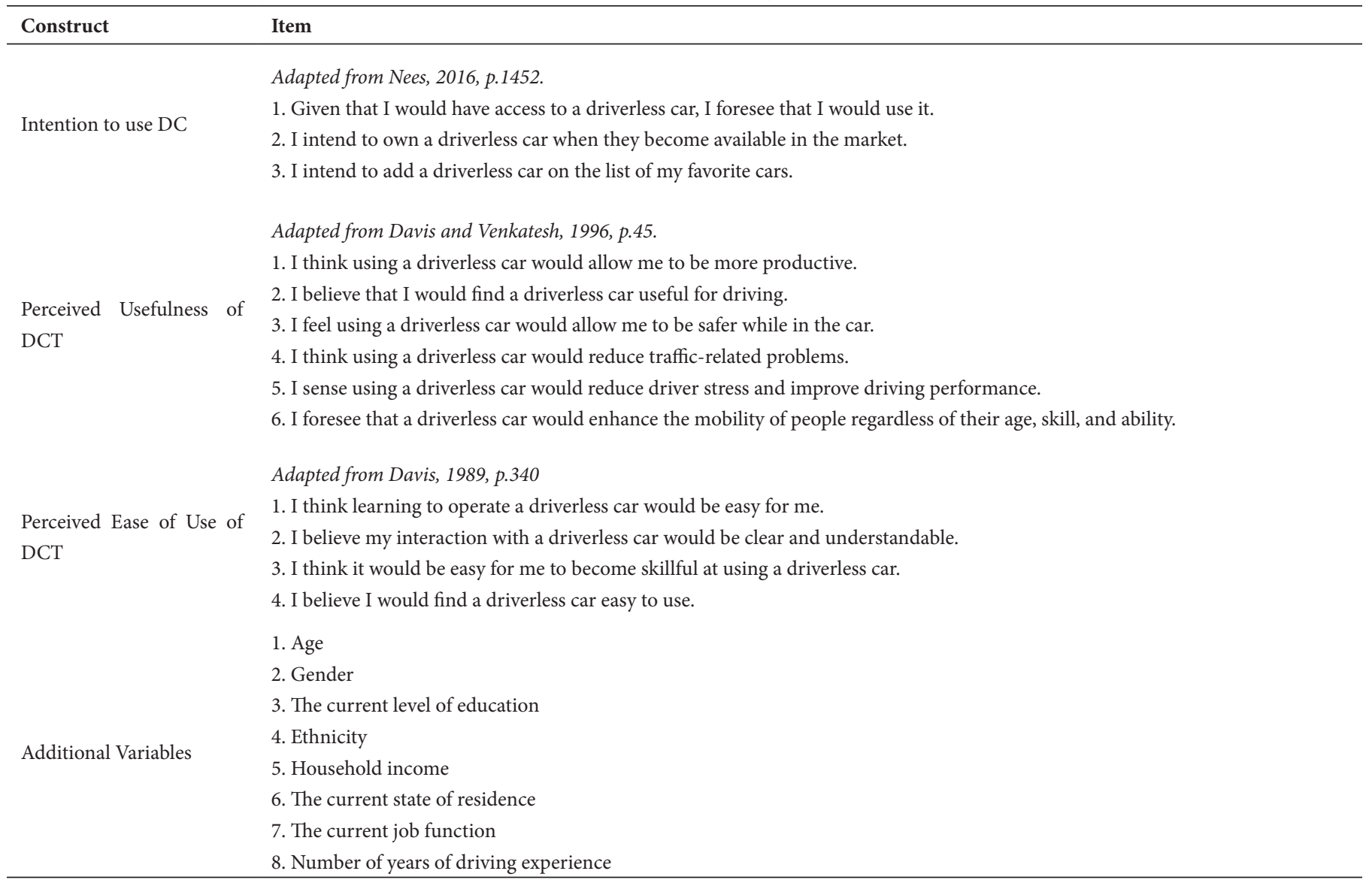

\section{Participants}

The employees working at a truck accessory manufacturer were the participants of this study. The organization has 13 subsidiaries located across various states within the U.S. The proportional stratified sampling method was utilized to select the sample $(\mathrm{n}=377)$ as different divisions were strata with unequal size. The sample embodied a diverse occupational background as shown in Figure 3. 
Figure 3. Distribution of Study Sample by Job Function.

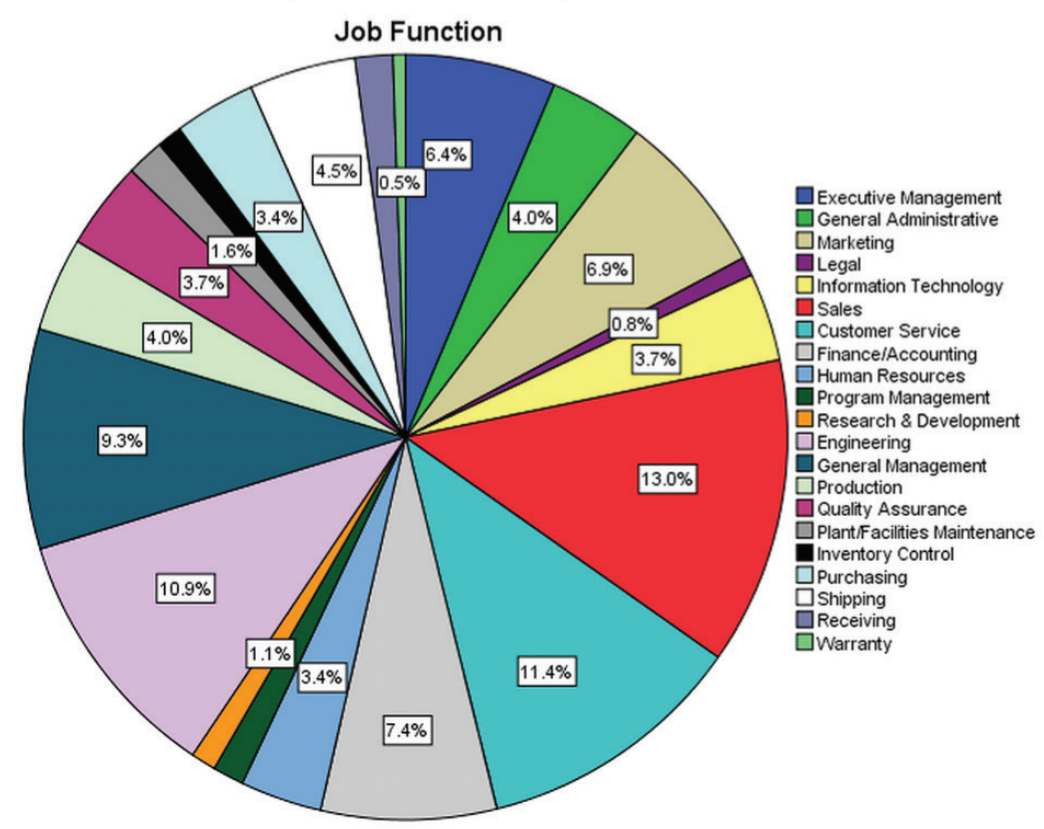

\section{Data Collection}

A link to Survey Monkey incorporating the study instrument was distributed via email to the sample located in all 13 subsidiaries of the selected organization across the U.S. For background information, the definition and picture of a DC along with a brief video on DCT were provided. The survey incorporated two dummy questions to assess the presence of mind of respondents. The survey remained open for ten business days.
Finally, a sample of 377 out of 567 responses was included in this study due to various reasons for exclusion, such as missing values, wrong answer on dummy questions, and outlier tests.

\section{Validity and Reliability}

The reason for the selection of 13 subsidiaries of the participant organization across the U.S. was to minimize threats to external validity, which could help in cautiously generalizing across a wider population. The distribution of the sample across various states of the U.S. is shown in Figure 4.

Figure 4. Sample by the State of Residence.

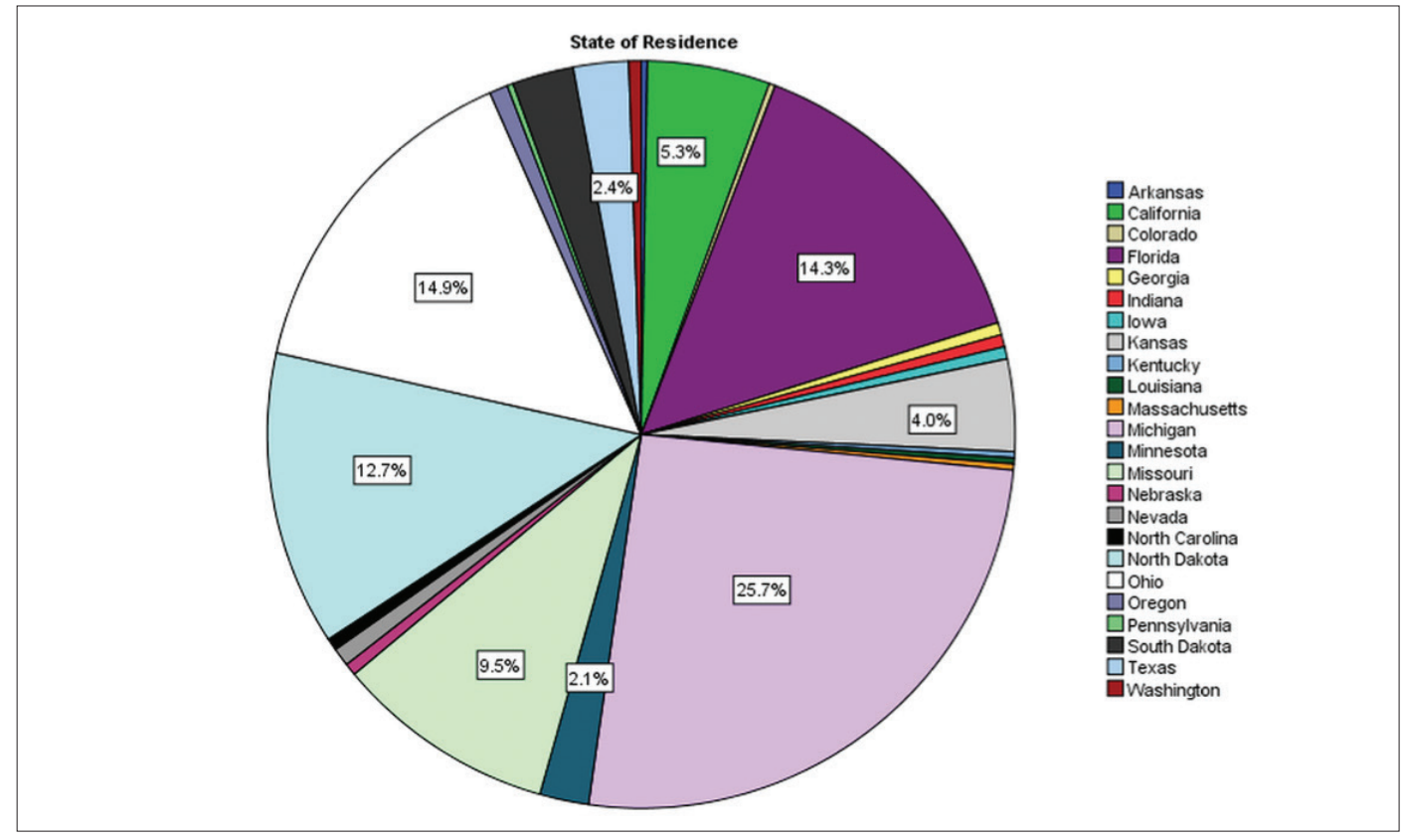


Out of the 377 responses used for this study, 20 (5.3\%) reported residing in California, 54 (14.3\%) in Florida, 15 (4.0\%) in Kansas, 97 (25.7\%) in Michigan, 36 (9.5\%) in Missouri, 48 (12.7\%) in North Dakota, and 56 (14.9\%) in Ohio.

Each construct was measured on a Likert-type scale of five points and five anchors. Cronbach's $\alpha>0.7$, as per academic quantitative research standards, was used to validate the scale's internal consistency. It was determined that the items used on the instrument have appropriate internal consistency as shown in Table 2.

Table 2. Reliability Analysis of the Instrument.

\begin{tabular}{lll}
\hline Scale & Cronbach's $\alpha$ & Number of Items \\
\hline Intention to use DC & 0.902 & 3 \\
Perceived usefulness of DCT & 0.896 & 6 \\
Perceived ease of use of DCT & 0.899 & 4 \\
\hline
\end{tabular}

\section{Analysis and Results}

We used the inferential statistical techniques shown in Table 3 to determine the strength and direction of the relationships between the perceived usefulness of DCT, perceived ease of use of DCT, years of driving experience, age and the intention to use DC. The Statistical Package for the Social Sciences (SPSS) 24.0 was used for performing the different statistical procedures.
Table 3. Data Analysis Approach

\begin{tabular}{ll}
\hline Research Question & Inferential Statistical Technique \\
\hline Q1 & Pearson Correlation \\
Q2 & Pearson Correlation \\
Q3 & Pearson Correlation \\
Q4 & Pearson Correlation \\
Q5 & Pearson Correlation \\
Q6 & Pearson Correlation \\
Q7 & Multiple Linear Regression \\
\hline
\end{tabular}

A preliminary examination of the data revealed that the assumptions of linearity, independence of errors, normal distribution, and collinearity were reasonably met.

\section{Demographic Analysis}

Demographic data of the participants that include gender, age, education level, ethnicity, and annual household income are presented in Table 4. Even though the number of male participants was more than double the number of female participants, due to the large sample size, we had sufficient female participants to test the moderation effects of this variable. Due to the nature of the data, the moderation effects of ethnicity variable were not included in this study.

Table 4. Participants' Demographics

\begin{tabular}{|c|c|c|c|}
\hline Variables & & Frequency & Percentage \\
\hline \multirow[t]{2}{*}{ Gender } & Male & 258 & $68.44 \%$ \\
\hline & Female & 119 & $31.56 \%$ \\
\hline \multirow[t]{8}{*}{ Age (years) } & $18-20$ & 07 & $1.86 \%$ \\
\hline & $21-24$ & 26 & $6.90 \%$ \\
\hline & $25-30$ & 67 & $17.77 \%$ \\
\hline & $31-34$ & 38 & $10.08 \%$ \\
\hline & $35-40$ & 59 & $15.65 \%$ \\
\hline & $41-50$ & 98 & $25.98 \%$ \\
\hline & $51-60$ & 60 & $15.92 \%$ \\
\hline & $60+$ & 22 & $5.84 \%$ \\
\hline \multirow[t]{6}{*}{ Education } & High School & 43 & $11.41 \%$ \\
\hline & Technical Training & 17 & $4.51 \%$ \\
\hline & Some College - No Degree & 103 & $27.32 \%$ \\
\hline & Associate Degree & 37 & $9.81 \%$ \\
\hline & Bachelor Degree & 144 & $38.20 \%$ \\
\hline & Graduate Degree & 33 & $8.75 \%$ \\
\hline \multirow[t]{8}{*}{ Ethnicity } & American Indian/ Alaskan Native & 4 & $1.06 \%$ \\
\hline & Asian/Pacific Islander & 6 & $1.59 \%$ \\
\hline & African American & 12 & $3.18 \%$ \\
\hline & Hispanic & 27 & $7.16 \%$ \\
\hline & Caucasian & 328 & $87.01 \%$ \\
\hline & $\$ 0-\$ 24,999$ & 12 & $3.18 \%$ \\
\hline & $\$ 25,000-\$ 49,999$ & 64 & $16.97 \%$ \\
\hline & $\$ 50,000-\$ 74,999$ & 72 & $19.10 \%$ \\
\hline \multirow{6}{*}{$\begin{array}{l}\text { Annual Household In- } \\
\text { come }\end{array}$} & $\$ 75,000$ - $\$ 99,999$ & 82 & $21.75 \%$ \\
\hline & $\$ 100,000-\$ 124,999$ & 65 & $17.24 \%$ \\
\hline & $\$ 125,000-\$ 149,999$ & 28 & $7.43 \%$ \\
\hline & $\$ 150,000-\$ 174,999$ & 17 & $4.51 \%$ \\
\hline & $\$ 175,000-\$ 199,999$ & 11 & $2.92 \%$ \\
\hline & $\$ 200,000+$ & 26 & $6.90 \%$ \\
\hline
\end{tabular}




\section{The Result of Research Questions}

Table 5 shows Pearson correlations between Perceived Usefulness of DCT, Perceived Ease of Use of DCT, Years of Driving Experience, Age and the Intention to use DC. The significance threshold for this study was set at $\mathrm{p} \leq 0.05$.

Table 5. Pearson Correlations among various constructs.

\begin{tabular}{ll}
\hline & Intention to Use DC \\
\hline Perceived Usefulness of DCT & $0.780^{* * *}$ \\
Perceived Ease of Use of DCT & $0.387^{* * *}$ \\
Years of Driving Experience & $-0.144^{* *}$ \\
Age & $-0.123^{*}$ \\
\hline
\end{tabular}

Note. $\dagger=\mathrm{p}<0.10, *=\mathrm{p}<0.05, * *=\mathrm{p}<0.01, * * *=\mathrm{p}<0.001$, and $\mathrm{n}=377$ for all analyses.
The results of the research questions analyses are shown in Table 6 . The SPSS output reflecting an overall multiple linear regression model summary and beta coefficients examining the impact on the dependent construct is shown in Table 7 and Table 8 , respectively. The beta values shown in Table 8 (B - Perceived Usefulness of DCT $=0.420$; $\mathrm{B}$ - Perceived Ease of Use of DCT $=0.127$; B - Years of Driving Experience $=-0.390$ ) represents the average change in a consumer's intentions to use DC for each increment change in the perceived usefulness of DCT, perceived ease of use of DCT, and years of driving experience, respectively. The beta value for age is not statistically significant and therefore, is not a predictor of consumer's intentions to use DC.

Table 6: The Results of Research Questions

Research Question
Q1: To what extent does a relationship exist between the perceived usefulness of DCT
and the intention to use DC?

Q2: To what extent does a relationship exist between the perceived ease of use of DCT and the intention to use DC?

Q3: To what extent does a relationship exist between the number of years of driving experience and the intention to use DC?

Q4: To what extent does a relationship exist between age and the intention to use DC?

Q5: To what extent do the socio-economic demographic variables (Gender, Level of Education, and Household Income) moderate the relationship between the perceived usefulness of DCT and the intention to use DC?

Q6: To what extent do the socio-economic demographic variables (Gender, Level of Education, and Household Income) moderate the relationship between the perceived ease of use of DCT and the intention to use DC?

Q7: What is the combined impact of perceived usefulness of DCT, perceived ease of use of DCT, number of years of driving experience, and age on the intention to use DC?
Statistical Analysis Result

The perceived usefulness of DCT and the intention to use DC have a strong, statistically significant positive relationship $(\mathrm{r}=0.780, \mathrm{n}=377, \mathrm{p}<0.001)$.

The perceived ease of use of DCT and the intention to use DC have a moderate, statistically significant positive relationship $(\mathrm{r}=0.387, \mathrm{n}=377, \mathrm{p}<0.001)$.

Years of driving experience and the intention to use DC have a weak, statistically significant negative relationship

( $\mathrm{r}=-0.144, \mathrm{n}=377, \mathrm{p}<0.01)$.

Age and the intention to use DC have a weak, statistically significant negative relationship $(\mathrm{r}=-0.123, \mathrm{n}=377, \mathrm{p}<0.05)$.

Gender, level of education, and household income were not found to have any moderating influence on the relationship between the perceived usefulness of DCT and the intention to use DC.

Gender as a moderator:

Male $(\mathrm{r}=0.774, \mathrm{n}=258, \mathrm{p}<0.001)$

Female $(\mathrm{r}=0.802, \mathrm{n}=119, \mathrm{p}<0.001)$.

Level of education as a moderator:

Low Education $(\mathrm{r}=0.817, \mathrm{n}=200, \mathrm{p}<0.001)$

High Education $(\mathrm{r}=0.747, \mathrm{n}=177, \mathrm{p}<0.001)$.

Household income as a moderator:

Low household income $(\mathrm{r}=0.822, \mathrm{n}=148, \mathrm{p}<0.001)$

Medium household income $(\mathrm{r}=0.729, \mathrm{n}=147, \mathrm{p}<0.001)$

High household income $(\mathrm{r}=0.811, \mathrm{n}=82, \mathrm{p}<0.001)$.

Gender, level of education, and household income were not found to have any moderating influence on the relationship between the perceived ease of use of DCT and the intention to use DC.

Gender as a moderator:

Male $(\mathrm{r}=0.377, \mathrm{n}=258, \mathrm{p}<0.001)$

Female $(\mathrm{r}=0.407, \mathrm{n}=119, \mathrm{p}<0.001)$.

Level of education as a moderator:

Low Education $(\mathrm{r}=0.406, \mathrm{n}=200, \mathrm{p}<0.001)$

High Education $(\mathrm{r}=0.364, \mathrm{n}=177, \mathrm{p}<0.001)$.

Household income as a moderator:

Low household income $(\mathrm{r}=0.340, \mathrm{n}=148, \mathrm{p}<0.001)$

Medium household income $(\mathrm{r}=0.446, \mathrm{n}=147, \mathrm{p}<0.001)$

High household income $(\mathrm{r}=0.353, \mathrm{n}=82, \mathrm{p}<0.01)$.

The multiple linear regression model sufficiently explains the dependent construct of intention to use DC

$\left(\mathrm{R}^{2}=0.622, \mathrm{n}=377, \mathrm{p}<0.001\right)$.

By evaluating $\mathrm{R}^{2}$, a statistical interpretation can be made that $62.2 \%$ of the variance in the intention to use DC is explained by the combination of the perceived usefulness of DCT, perceived ease of use of DCT, and years of driving experience. 
Table 7. Multiple Regression Model Summary

\begin{tabular}{|c|c|c|c|c|c|c|c|c|c|c|c|}
\hline \multirow[b]{2}{*}{ Model } & \multirow[b]{2}{*}{$\mathrm{R}$} & \multirow[b]{2}{*}{ R Square } & \multirow{2}{*}{$\begin{array}{l}\text { Adjusted R Squa- } \\
\text { re }\end{array}$} & \multirow{2}{*}{\multicolumn{2}{|c|}{$\begin{array}{l}\text { Std. Error of the Es- } \\
\text { timate }\end{array}$}} & \multicolumn{5}{|c|}{ Change Statistics } & \multirow{2}{*}{$\begin{array}{l}\text { Durbin } \\
\text { Watson }\end{array}$} \\
\hline & & & & & & Change & F Change & df1 & $\mathrm{df} 2$ & Sig. F Change & \\
\hline 1 & .791 & 0.626 & 0.622 & 2.329 & \multicolumn{2}{|c|}{0.626} & 155.781 & 4 & 372 & 0.000 & 1.942 \\
\hline \multirow{3}{*}{ Model } & & \multicolumn{2}{|c|}{$\begin{array}{l}\text { Unstandardized } \\
\text { Coefficients }\end{array}$} & $\begin{array}{l}\text { Standardized } \\
\text { Coefficients }\end{array}$ & \multirow{2}{*}{$\mathrm{t}$} & \multirow{2}{*}{ Sig. } & $\begin{array}{l}95.0 \% \mathrm{Co} \\
\text { Interval f }\end{array}$ & dence & & \multicolumn{2}{|c|}{ Collinearity Statistics } \\
\hline & & B & $\begin{array}{l}\text { Std. } \\
\text { Error }\end{array}$ & Beta & & & $\begin{array}{l}\text { Lower } \\
\text { Bound }\end{array}$ & $\begin{array}{l}\text { Upper } \\
\text { Bound }\end{array}$ & & Tolerance & $\begin{array}{l}\text { Variance } \\
\text { Inflated } \\
\text { Factor }\end{array}$ \\
\hline & $\begin{array}{l}\text { (Constant) } \\
\text { Perceived }\end{array}$ & -1.943 & 0.742 & & -2.617 & 0.009 & -3.403 & -0.483 & & & \\
\hline \multirow{4}{*}{1} & $\begin{array}{l}\text { Usefulness of } \\
\text { DCT }\end{array}$ & 0.420 & 0.020 & 0.732 & 21.385 & 0.000 & 0.382 & 0.459 & & 0.818 & 1.166 \\
\hline & $\begin{array}{l}\text { Perceived Ease } \\
\text { of Use of DCT }\end{array}$ & 0.127 & 0.037 & 0.117 & 3.436 & 0.001 & 0.054 & 0.200 & & 0.861 & 1.162 \\
\hline & $\begin{array}{l}\text { Years of } \\
\text { Driving Expe- } \\
\text { rience }\end{array}$ & -0.390 & 0.186 & -0.193 & -2.097 & 0.037 & -0.756 & -0.024 & & 0.119 & 8.409 \\
\hline & Age & 0.317 & 0.196 & 0.149 & 1.616 & 0.107 & -0.069 & 0.702 & & 0.119 & 8.418 \\
\hline
\end{tabular}

\section{Comparative Analyses}

The existing research findings have indicated that the TAM constructs of Perceived Usefulness and Perceived Ease of Use are significant factors for anticipating future usage of different technologies across various settings (Davis \& Venkatesh, 1996; Dillon \& Morris, 1996; Drennan, Kennedy, and Pisarski, 2005; Lee et al., 2003; Park, Kim, Shon, and Shim, 2013). These findings are consistent with the findings of this study that revealed as the perception of usefulness associated with DCT increased, the intentions of potential consumers to use DC strongly increased. Also, as the perception of ease of use associated with DCT increased, the intentions of the potential consumers to use DC moderately increased.

Thus, due to the strongest correlation in this study, it is proposed that the perceived usefulness construct be served as a noteworthy focus area for the marketers of DCT. Also, it is speculated that once usefulness of DC technology is established, consumers may put forth the effort required to learn this technology. However, Lane and Coleman (2012) found that higher Perceived Ease of Use led to higher Perceived Usefulness, which ultimately led to higher usage of technology.

This work found that as consumers' years of driving experience increased, the intentions of potential consumers to use DC decreased slightly. Also, the data revealed that with an increase in consumers' age, the intentions of potential consumers to use DC decreased slightly. These findings are consistent with existing research that the acceptance of DCT is lower in consumers with more driving experience and with older consumers (Nees, 2016).

\section{Conclusion and Future Studies}

The regression model had sufficient explanatory power with each construct, except age, is a significant predictor of consumers' behavioral intention to use DC. The Perceived Usefulness construct was shown to be the strongest predictor of intention to use DC. The constructs of the TAM framework provided a robust theoretical base for predicting DC adoption.

In the coming years, seniors are projected to constitute the majority of the U.S. population and, hence, are one of the biggest consumer bases for automobile manufacturers in the future. Therefore, it becomes of paramount significance for DCT manufacturers to develop and implement interventions in advance that will help reduce the impact of age on the intention to use DC.

This study was limited to determining only the relationships between the constructs under examination and could not predict causation. Also, Arts, Frambach and Bijmolt (2011) cautioned that, with multifaceted technological innovations, the measured adoption behavioral intention might reflect higher levels than actual adoption.

Future studies of DCT adoption may include the construct of selfefficacy as a mediating variable between the relationship of Perceived Ease of Use of DCT and intention to use DC. The level of a person's self-efficacy may mediate the relationship between Perceived Ease of Use and behavioral intentions. Even though customer resistance to innovation was not included in this study, this construct may be significant for future studies on DCT adoption research. Also, future studies can examine the impact of a user's level of experience with 
currently available automotive technology, such as those specified in National Highway Traffic Safety Administration (NHTSA) level three category (e.g., lane assist, brake assist), on the intention to use DC. Moreover, a user's level of experience with currently available automotive technology may mediate the relationship between the Perceived Ease of Use of DCT and the intention to use DC. Finally, the degree to which consumers are willing to give up their driving control could be a significant factor to be considered in future studies.

\section{References}

Arts, J. W. C., Frambach, R. T., \& Bijmolt, T. H. A. (2011). Generalizations on consumer innovation adoption: A meta-analysis on drivers of intention and behavior. International Journal of Research in Marketing, 28(2), 134-144. https://doi.org/10.1016/j.ijresmar.2010.11.002

Bansal, P. Kockelman, K. M. and Singh, A. (2016). Assessing public opinions of and interest in new vehicle technologies: An Austin perspective. Transportation Research Part C: Emerging Technologies, 67, 1-14. https://doi.org/10.1016/j.trc.2016.01.019

Brett, J. A. (2016). Thinking local about self-driving cars: A local framework for autonomous vehicle development in the United States (Master's thesis). Retrieved from ProQuest Dissertations and Theses Global. (UMI No. 10138698). http://search.proquest.com/pqdtglobal/docview/1804414282/abstract/D74E736B56B840B8PQ/8

Davis, F. D. (1989). Perceived usefulness, perceived ease of use, and user acceptance of information technology. MIS Quarterly, 13(3), 319-340. https://doi.org/10.2307/249008

Davis, F. D. (1993). User acceptance of information technology: System characteristics, user perceptions, and behavioral impacts. International Journal of Man-Machine Studies, 38(3), 475-487. https://doi. org/10.1006/imms.1993.1022

Davis, F. D., \& Venkatesh, V. (1996). A critical assessment of potential measurement biases in the Technology Acceptance Model: Three experiments. International Journal of Human-Computer Studies, 45(1), 19-45. https://doi.org/10.1006/ijhc.1996.0040

Dillon, A., \& Morris, M. G. (1996). User acceptance of new information technology: Theories and models. Annual Review of Information Science and Technology, 14(4), 3-32. Retrieved from

http://hdl.handle.net/10150/105584

Drennan, J., Kennedy, J., \& Pisarski, A. (2005). Factors affecting student attitudes toward flexible online learning in management education. The Journal of Educational Research, 98(6), 331-338. https://doi. org/10.3200/JOER.98.6.331-338

Gadepally, V. N. (2013). Estimation of driver behavior for autonomous vehicle applications (Doctoral dissertation). Retrieved from ProQuest Dissertations and Theses Global. (UMI No. 3671348). http:// search.proquest.com/pqdtglobal/docview/1647127404/abstract/ D74E736B56B840B8PQ/11
Ghazizadeh, M., Lee, J. D., \& Boyle, L. N. (2012). Extending the Technology Acceptance Model to assess automation. Cognition, Technology \& Work, 14(1), 39-49. https://doi.org/10.1007/s10111-011-0194-3

Guerra, E. (2016). Planning for cars that drive themselves: Metropolitan planning organizations, regional transportation plans, and autonomous vehicles. Journal of Planning Education and Research, 36(2), 210-224. https://doi.org/10.1177/0739456X15613591

Heide, A. and Henning, K. (2006). The "cognitive car": A roadmap for research issues in the automotive sector. Annual Reviews in Control, 30(2), 197-203. https://doi.org/10.1016/j.arcontrol.2006.09.005

Holden, R. J., \& Karsh, B. T. (2010). The Technology Acceptance Model: Its past and its future in health care. Journal of Biomedical Informatics, 43(1), 159-172. https://doi.org/10.1016/j.jbi.2009.07.002

Horton, R. P., Buck, T., Waterson, P. E., \& Clegg, C. W. (2001). Explaining intranet use with the Technology Acceptance Model. Journal of Information Technology, 16(4), 237-249. https://doi. org/10.1080/02683960110102407

Howard, D. and Dai D. (2014). Public perceptions of self-driving cars: The case of Berkeley, California. In Transportation Research Board 93rd Annual Meeting, No. 14-4502. Retrieved from http://cet.berkeley.edu/wp-content/uploads/Self-Driving-Cars.pdf

Jansson, J., Marell, A., \& Nordlund, A. (2010). Green consumer behavior: Determinants of curtailment and eco-innovation adoption. Journal of Consumer Marketing, 27(4), 358-370. https://doi. org/10.1108/07363761011052396

Jiang, T., Petrovic, S., Ayyer, U., Tolani, A., \& Husain, S. (2015). Selfdriving cars: Disruptive or incremental (No. 2013.05.29) (pp. 3-22). Berkeley: University of California Fung Institute for Engineering Leadership. Retrieved from http://www.funginstitute.berkeley.edu/sites/ default/!les/Self_Driving_Cars.pdf

Knight, W. (2013). Driverless cars. Technology Review; Cambridge, 116(6), 44-49. Retrieved from http://search.proquest.com/docview/1459693183/abstract/5F0127A756E64882PQ/1

Lane, M., \& Coleman, P. (2012). Technology ease of use through social networking media. Journal of Technology Research, 3(1), 1-12. Retrieved from

http://search.proquest.com/openview/070df63945c48ea6c4102942af d61ff8/1.pdf?pq-origsite $=$ gscholar\&cbl=237733

Lee, Y., Kozar, K. A., \& Larsen, K. R. (2003). The Technology Acceptance Model: Past, present, and future. Communications of the Association for Information Systems, 12(50), 750-782. Retrieved from http:// aisel.aisnet.org/cgi/viewcontent.cgi? article $=3217 \&$ context $=$ cais

Li, L. (2010). A critical review of technology acceptance literature. Grambling State University, 19(1), 1-20. Retrieved from http://www. swdsi.org/swdsi2010/sw2010_preceedings/papers/pa104.pdf 
López-Nicolás, C., Molina-Castillo, F. J., \& Bouwman, H. (2008). An assessment of advanced mobile services acceptance: Contributions from TAM and diffusion theory models. Information \& Management, 45(6), 359-364. https://doi.org/10.1016/j.im.2008.05.001

Maarafi, A. (2015). The impact of autonomous vehicles on freeway throughput (Master's thesis). Retrieved from ProQuest Dissertations and Theses Global. (UMI No. 1596625). Retrieved from http:// search.proquest.com/pqdtglobal/docview/1708380668/abstract/ D74E736B56B840B8PQ/4

Matthews, M. C. (2016). Intent communication between autonomous vehicles and humans (Master's thesis). Retrieved from ProQuest Dissertations and Theses Global. (UMI No. 10189053). Retrieved from http://search.proquest.com/pqdtglobal/docview/1854866974/abstract/D74E736B56B840B8PQ/35

Menon, N. (2015). Consumer perception and anticipated adoption of autonomous vehicle technology: Results from multi-population surveys (Master's thesis). Retrieved from ProQuest Dissertations and Theses Global. (UMI No. 1603803). Retrieved from http:// search.proquest.com/pqdtglobal/docview/1734473356/abstract/ D74E736B56B840B8PQ/44

Mohd, F., Ahmad, F., Samsudin, N., \& Sudin, S. (2011). Extending the Technology Acceptance Model to account for social influence, trust, and integration for pervasive computing environment: A case study in the university industry. American Journal of Economics and Business Administration, 3(3), 552-559. Retrieved from http://search. proquest.com/openview/bcb1c53cdac2c8892bbe001a94052176/1? pq-origsite $=$ gscholar $\& \mathrm{cbl}=1216358$

Nees, M. A. (2016). Acceptance of self-driving cars: An examination of idealized versus realistic portrayals with a self-driving car acceptance scale. Proceedings of the Human Factors and Ergonomics Society Annual Meeting, 60(1), 1449-1453. https://doi. org/10.1177/1541931213601332

Owczarzak, Ł. and Żak, J. (2015). Design of passenger public transportation solutions based on autonomous vehicles and their multiple criteria comparison with traditional forms of passenger transportation. Transportation Research Procedia, 10(2015), 472-482. https:// doi.org/10.1016/j.trpro.2015.09.001

Park, N., Kim, Y. C., Shon, H. Y., \& Shim, H. (2013). Factors influencing smartphone use and dependency in South Korea. Computers in Human Behavior, 29(4), 1763-1770. https://doi.org/10.1016/j. chb.2013.02.008

Payre, W. Cestac, J. and Delhomme, P. (2014). Intention to use a fully automated car: Attitudes and a priori acceptability. Transportation Research Part F: Traffic Psychology and Behaviour, 27(2014), 252-263. https://doi.org/10.1016/j.trf.2014.04.009
Schoettle, B., \& Sivak, M. (2014). A survey of public opinion about autonomous and self-driving vehicles in the US, the UK, and Australia (No. UMTRI-2014-21). Ann Arbor: University of Michigan Transportation Research Institute. Retrieved from https://deepblue.lib. umich.edu/handle/2027.42/108384

Thrun, S., Montemerlo, M., Dahlkamp, H., Stavens, D., Aron, A., Diebel, J., ... Mahoney, P. (2006). Stanley: The robot that won the DARPA grand challenge. Journal of Field Robotics, 23(9), 661-692. https://doi. org/10.1002/rob.20147

Venkatesh, V., Davis, F. D., \& Morris, M. G. (2007). Dead or alive? The development, trajectory, and future of technology adoption research. Journal of the Association for Information Systems, 8(4), 267-286.

Retreievd from

http://search.proquest.com/openview/3ccfb894c4987572e5b9c4f899 3b4c63/1?pq-origsite $=$ gscholar $\& \mathrm{cbl}=26427$

Yang, K. C. C. (2005). Exploring factors affecting the adoption of mobile commerce in Singapore. Telematics and Informatics, 22(3), 257-277. https://doi.org/10.1016/j.tele.2004.11.003

Yousafzai, S. Y., Foxall, G. R., \& Pallister, J. G. (2007). Technology acceptance: A meta-analysis of the TAM: Part 1. Journal of Modelling in Management, 2(3), 251-280. https://doi. org/10.1108/17465660710834453

Zindler, K. and Geiss, N. (2016). Vehicle ego-localization in autonomous lane-keeping evasive maneuvers. IFAC-PapersOnLine, 49(11), 160-167. https://doi.org/10.1016/j.ifacol.2016.08.025

\section{Biography}

Sahil Koul received his Ph.D. in Technology from Eastern Michigan University, USA and M.S degree in Automotive Engineering from Lawrence Technological University, USA. His research interests are in interdisciplinary areas of automotive technologies including driverless car technology, technology acceptance and diffusion of emerging technologies, and examining socio-technological interactions. He has over ten years of experience in working within the automotive domain and at present, works as an engineering manager for a large North American automotive accessory manufacturer.

Ali Eydgahi started his career in higher education as a faculty member at the Rensselaer Polytechnic Institute in 1985. Since then, he has been with the State University of New York, University of Maryland Eastern Shore, and Eastern Michigan University. During 2006-2010, he was Chair of the Department of Engineering and Aviation Sciences, Founder and Director of the Center for 3-D Visualization and Virtual Reality Applications, and Technical Director of the NASAfunded MIST Space Vehicle Mission Planning Laboratory at the University of Maryland Eastern Shore. In 2010, he joined Eastern Michigan University as an Associate Dean in the College of Technology 
and currently is a Professor in the School of Engineering Technology. He has extensive experience in curriculum and laboratory design and development. Dr. Eydgahi has served as a member of the Board of Directors of Tau Alpha Pi and as a member of advisory and editorial boards for many international journals in engineering and techno- logy. Also, he has served as a member of the review panel for NASA and Department of Education, as a regional and chapter chairman of IEEE, SME, and ASEE, and as a session chair and a member of scientific and international committees for many international conferences. 